\title{
A comparative study of anti-Trypanosoma cruzi serum obtained in acute and chronic phase of infection in mice
}

\author{
Harumi A. Takehara, Ana M. M. Da Silva, Claudia I. Brodskyn and I. Mota \\ Immunology Research and Training Center, Instituto Butantan, São Paulo, Brazil
}

(Received 13 April 1989; revision received 14 August 1989; accepted 19 August 1989)

\section{Summary}

The IgG antibody content, specificity, lytic activity, clearance capacity and protective ability of mouse anti-Trypanosoma cruzi serum was determined during the course of infection. The IgG antibody content increased during the course of infection, reaching its highest level in the serum collected in the chronic phase of the infection. The T. cruzi antigens recognized by antibodies using the protein transfer technique also increased with time of infection. Antibodies present in day 22 post-infection (p.i.) serum were already able to recognize all the antigens detected by antibodies present in serum from the chronic phase. The lytic and clearance ability were not detected on day 7 p.i., but appeared on day 14 p.i. and reached their highest level on day 45 p.i. The protective ability was present in serum of the chronic phase, but was absent from the acute serum. The IgG antibody content of the acute serum was four times less than that of the chronic serum. When the IgG antibody concentration of the acute serum was equalized to that of the chronic serum, the acute serum was as able to protect the infected animals as the chronic serum. It is suggested that the disagreement between the protective ability of anti-T. cruzi antisera collected in the acute or in the chronic phase of the infection is due to a quantitative rather than a qualitative difference.

Key words: Trypanosoma cruzi; IgG anti-T. cruzi; Antibody, Immunity

Correspondence to: Dr. H. A. Takehara, Immunology Research and Training Center, Instituto Butantan, Avenida Vital Brasil 1500, CP 65, 35503 São Paulo, SP, Brazil.

\section{Introduction}

Infection of humans and mice with $T$. cruzi induces a strong humoral immune response mostly mediated by IgG antibodies [1-3]. Passive transfer of sera or IgG antibodies obtained from mice in the chronic phase of the infection confers a significant protection against death induced by an otherwise fatal challenge with the parasites $[4,1]$. However, sera collected in the acute phase of the infection have no protective ability [5]. The reason for that difference in the protective ability of the acute and chronic sera is not known.

In the present paper, we made a comparative study of mouse anti-T. cruzi sera obtained during the acute and chronic phases of the infection, determining their IgG antibody content, specificity, lytic activity and clearance capacity, and attempting to correlate these properties with the serum protective ability.

\section{Materials and Methods}

\subsection{Animals}

Inbred $\mathrm{A} / \mathrm{Sn}$ mice weighing $16-20 \mathrm{~g}$ were used. Although animals of both sexes were used throughout the work, within each experiment the animals were of a single sex.

\subsection{Parasites}

The Y strain of T. cruzi [6] maintained in mice by weekly passages was used throughout. 


\subsection{Acute immune sera (AIS)}

Normal mice were injected i.p. with an infective dose of $10 \mathrm{~T}$. cruzi bloodstream trypomastigotes (Btrys). In order to obtain AIS the animals were bled 7,14 and 22 days after infection.

\subsection{Chronic immune sera}

Normal mice were infected with 10 Btrys and treated with nifurtimox as previously described [1]. 10 to 15 days after infection the animals were bled to determine whether parasites were present in their blood. Animals not showing parasites were eliminated from the experiment; those showing parasites were kept for 45 days when they were bled. These animals were considered to be in the chronic phase of the disease, since they presented low parasitaemia, high antibody level and resisted challenge with a lethal dose of Btrys.

\subsection{Hyperimmune serum}

In order to obtain hyperimmune serum (HIS), animals infected as described for the preparation of chronic immune sera (CIS) were kept for 45 days when they were challenged i.p. three times, one week apart with 100 Btrys and were bled 7 days after the last infectant dose.

\subsection{Preparation of antibody-free trypomastigotes}

In order to suppress antibody production mice were treated with cyclophosphamide $(350 \mathrm{mg} / \mathrm{kg})$ i.p. $72 \mathrm{~h}$ after having received a dose of $3 \times 10^{4}$ Btrys i.p. Seven days after infection the animals were bled and the Btrys isolated as described by Umekita et al. [7]. To exclude the presence of membranebound antibodies, the isolated Btrys were incubated with complement (fresh human serum) for $30 \mathrm{~min}$ at $37^{\circ} \mathrm{C}$. Only suspensions of parasites not lysed in presence of complement were considered free of antibodies.

\subsection{IgG antibody titration}

The anti-T. cruzi IgG antibody content of either acute of chronic sera was determined by ELISA using an extract of cultured epimastigotes as antigen
[8], anti-mouse IgG labelled with horse peroxidase (Sigma, St. Louis, MO, U.S.A.) as enzyme conjugate and $\mathrm{Opd} / \mathrm{H}_{2} \mathrm{O}_{2}$ as substrate. The absorbance of the wells were determined at $492 \mathrm{~nm}$ with an ELISA plate reader (Uniskan, Eflab, Finland).

\subsection{Antibody specificity}

The antibody specificity of the acute and chronic sera was determined by the western blotting technique using Btrys isolated by the CM cellulose method as described by Silva et al. [9] as antigen.

\subsection{Determination of lytic activity}

The presence of lytic antibody was determined by complement-mediated lysis, according to Krettli [10].

\subsection{Determination of immune clearance}

To measure the speed of disappearance of the Btrys from the peripheral blood, normal mice were injected in the tail vein with $0.2 \mathrm{ml} 0.15 \mathrm{M} \mathrm{NaCl}$ containing $2 \times 10^{6}$ antibody-free Btrys. $15 \mathrm{~min}$ later the animals were bled by puncture of the ophthalmic plexus and the number of parasites in circulation determined (time 0 ). Immediately after that the animals were injected intravenously (i.v.) with immune serum or immunoglobulin preparation, samples of blood were collected at different times by puncture of the ophthalmic plexus, and the number of parasites determined as described by Brener [11].

\subsection{Determination of protective ability}

Groups of mice were injected i.v. with either normal, acute or chronic mouse serum, and were infected $24 \mathrm{~h}$ later with 20 Btrys freshly isolated from the blood of donors infected 7 days previously with $10 \times 10^{4}$ parasites. The parasitaemia and mortality of the animals were determined and used as criteria for protection.

\section{Results}

\subsection{IgG anti-T. cruzi antibodies}

The development of anti-T. cruzi IgG antibodies 
was followed by ELISA in sera samples obtained at different days of infection. As can be seen in Table 1 , there was a gradual increase in he content of anti-T. cruzi IgG antibodies in the course of the infection, which reached its highest level in the chronic serum. Hyperimmunisation did not increase this level.

\subsection{IgG antibody specificity}

Representative reactions of the sera from acutely infected, chronically infected or hyperimmunised mice with Btrys antigen are shown in Fig. 1. The number of bands detected by the antibodies present in the sera of infected mice increased with time of infection. A faint but detectable line of antibody to peptides of about $100 \mathrm{kDa}$ was found early on the 7 th day p.i. From day 14 p.i., antibodies present in the sera were already able to recognise all the antigens in the region above $70 \mathrm{kDa}$. Sera from day 22 p.i. recognised the same high- $M_{\mathrm{r}}$ antigens as the sera of chronically infected mice ( 45 days p.i.). The few differences obtained in the low- $M_{\mathrm{r}}$ antigens were related to bands that were only occasionally stained with sera of chronically infected mice (not shown). The hyperimmune serum showed a higher number of low molecular antigens than the chronic serum.

\subsection{Lytic activity}

As shown in Table 1, the lytic activity was not detected early on day 7 p.i., but did appear on day 14 p.i. and reached the same level as in the chronic or hyperimmune serum on day 22 p.i.

\section{TABLE 1}

Summary data on the activities of the acute and chronic anti- $T$. cruzi serum.

\begin{tabular}{lcccc}
\hline $\begin{array}{l}\text { Serum collected } \\
\text { at day }\end{array}$ & $\begin{array}{l}\text { IgG titre Lytic } \\
\text { (ELISA) }\end{array}$ & $\begin{array}{l}\text { Clearance Protective } \\
\text { ability }\end{array}$ & $\begin{array}{l}\text { ability } \\
\text { abo }\end{array}$ \\
\hline 7 (acute) & 40 & 0 & 10 & 0 \\
14 (acute) & 160 & 60 & 34 & 0 \\
22 (acute) & 320 & 94 & 67 & 0 \\
22 (acute $4 \times$ & & & & \\
$\quad$ concentrated) & 1280 & ND & 100 & 50 \\
45 (chronic) & 1280 & 93 & 100 & 40 \\
73 (hyperimmune) & 1280 & 95 & 100 & 50 \\
\hline
\end{tabular}

ND, not determined; ${ }^{a} \%$ of removed Btrys after $1 \mathrm{~h} ;$ b $\%$ of survival up to 30 days p.i.

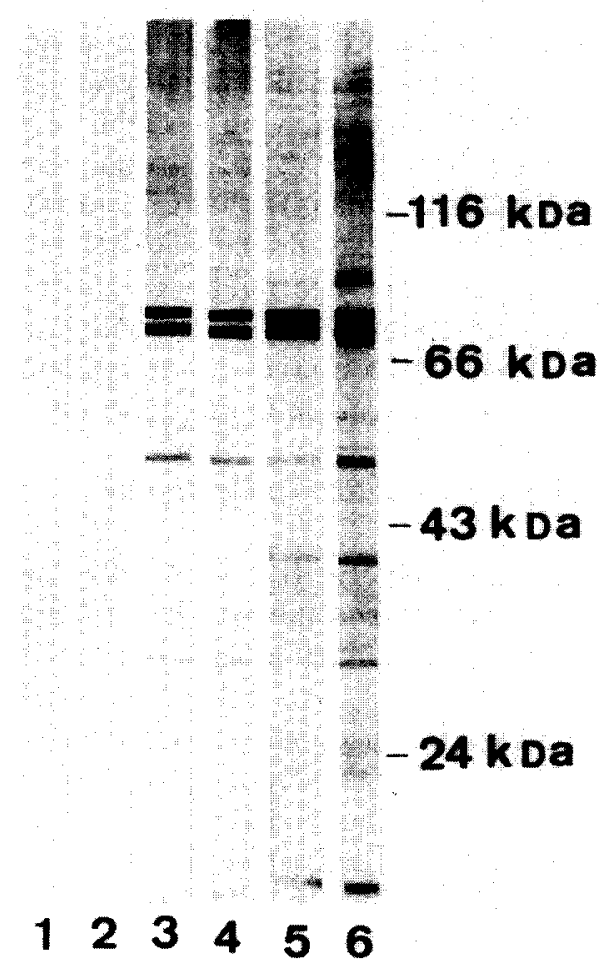

Fig. 1. Antigens of Btrys fractionated by SDS-PAGE recognised by normal mouse serum (1); serum from the 7th day p.i. (2); serum from the 14th day p.i. (3); serum from the 22 nd day p.i. (4); chronic serum (5); and hyperimmune serum (6). $M_{\mathrm{I}}$ values are shown on the right.

\subsection{Clearance ability}

As can be seen in Table 1, there was a gradual increase in the ability of the anti-T. cruzi sera to induce immune clearance during the course of infection, which was undetected on day 7 p.i., appeared first on day 14 p.i., increased up to day 22 p.i., and reached a maximum in the chronic serum. Hyperimmunisation did not change the serum clearance ability.

\subsection{Protective ability}

To determine the protective ability of anti-T. cruzi serum during the course of infection, groups of normal mice were injected i.v. with $0.4 \mathrm{ml}$ of acute (collected on days 7,14 and 22 p.i.), chronic, hyperimmune or normal sera. $24 \mathrm{~h}$ later, the animals were 
injected i.p. with an infectant dose of 20 Btrys. The parasitaemia and mortality of the animals are shown in Fig. 2. As can be seen, all animals pretreated with acute sera, although showing a slight decrease in parasitaemia on day 12 p.i., soon reached a parasitaemia level similar to that of controls on day 17 p.i. In addition, it can also be seen that the mortality in these animals was similar to that in control animals. Only animals pre-treated with chronic or hyperimmune serum presented a remarkable diminution in their parasitaemia and mortality.

\subsection{Effect of antibody concentration}

Inspection of the ELISA titres shown in Table 1 indicates that the chronic and hyperimmune sera have an antibody content at least four times greater than that of the acute sera. To find out whether this quantitative difference could explain the lack of protective ability of the acute serum, the serum collected on day 22 p.i. was precipitated with $33 \%$ ammonium sulphate, and after dialysis to remove the sulphate, the precipitated immunoglobulin was re-dissolved in a volume of $0.15 \mathrm{M} \mathrm{NaCl}$ so as to attain the same ELISA titre as the chronic sera. This required the immunoglobulins to be concentrated to a volume four times less than the original serum volume. Unfortunately, it was not possible to treat the sera from days 7 and 14 p.i. in the same way, because concen- tration of their immunoglobulin fraction to attain the antibody concentration of the chronic serum resulted in a solution too thick to be handled. The immunoglobulins of the chronic serum were precipitated in the same way but were re-dissolved in $0.15 \mathrm{M}$ $\mathrm{NaCl}$ to the original serum volume. Normal mouse serum immunoglobulins precipitated and redissolved with the same volume of $0.15 \mathrm{M} \mathrm{NaCl}$ used for the acute serum, were used as control. The protective ability of the acute serum before and after concentration was then determined and compared with that of the chronic and normal serum. The results of these experiments are shown in Table 1 and Fig. 3. As can be seen, when the antibody concentration of the acute serum (day 22 p.i.) was made similar to that of the chronic serum, its clearance and protective ability became as effective as those of the chronic serum.

\section{Discussion}

The results show that there is not much qualitative difference between the antibody specificity, clearance ability and the lytic activity of the acute and chronic sera, except for a dissociation between the lytic activity and the protective ability of the acute serum. In fact, the most marked difference between the acute and chronic sera was in their protective ability, which was absent at first, but present in the

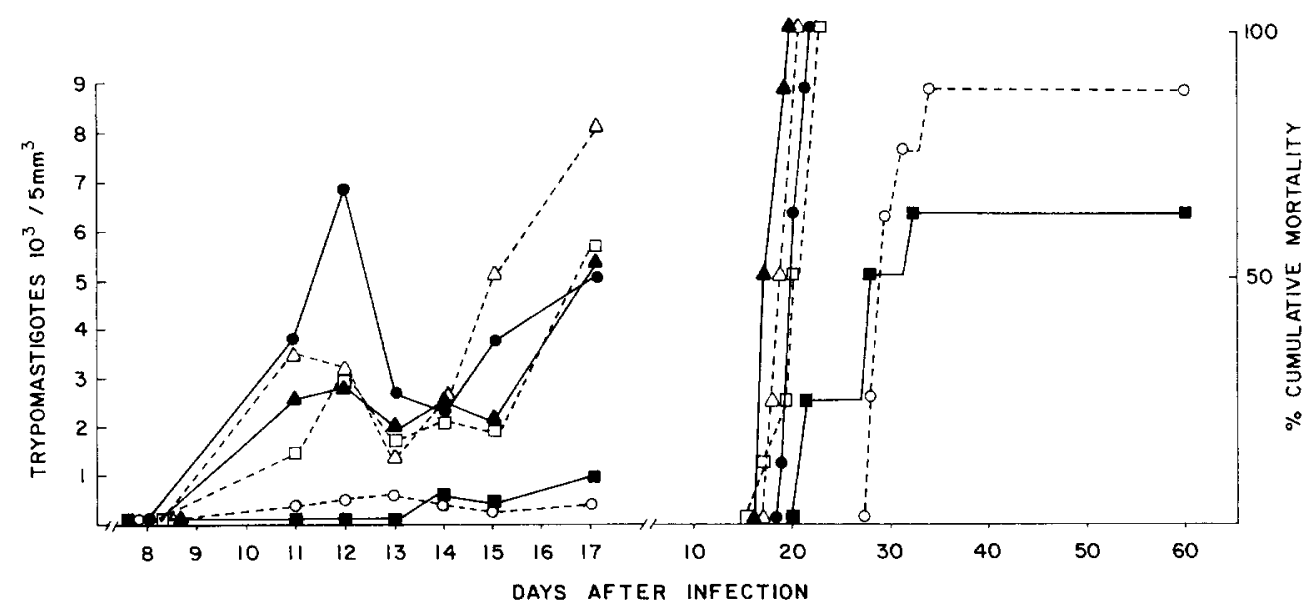

Fig. 2. Parasitaemia and mortality of mice pre-treated with anti-T. cruzi serum. The animals were injected with $0.4 \mathrm{ml}$ of: $\bullet$, normal mouse serum; $\Delta$, serum from 7 th day p.i.; 4 , serum from 14 th day p.i.; $\square$, serum from 22 nd day p.i.; 0 , chronic serum; and $\square$, hyperimmune serum. 


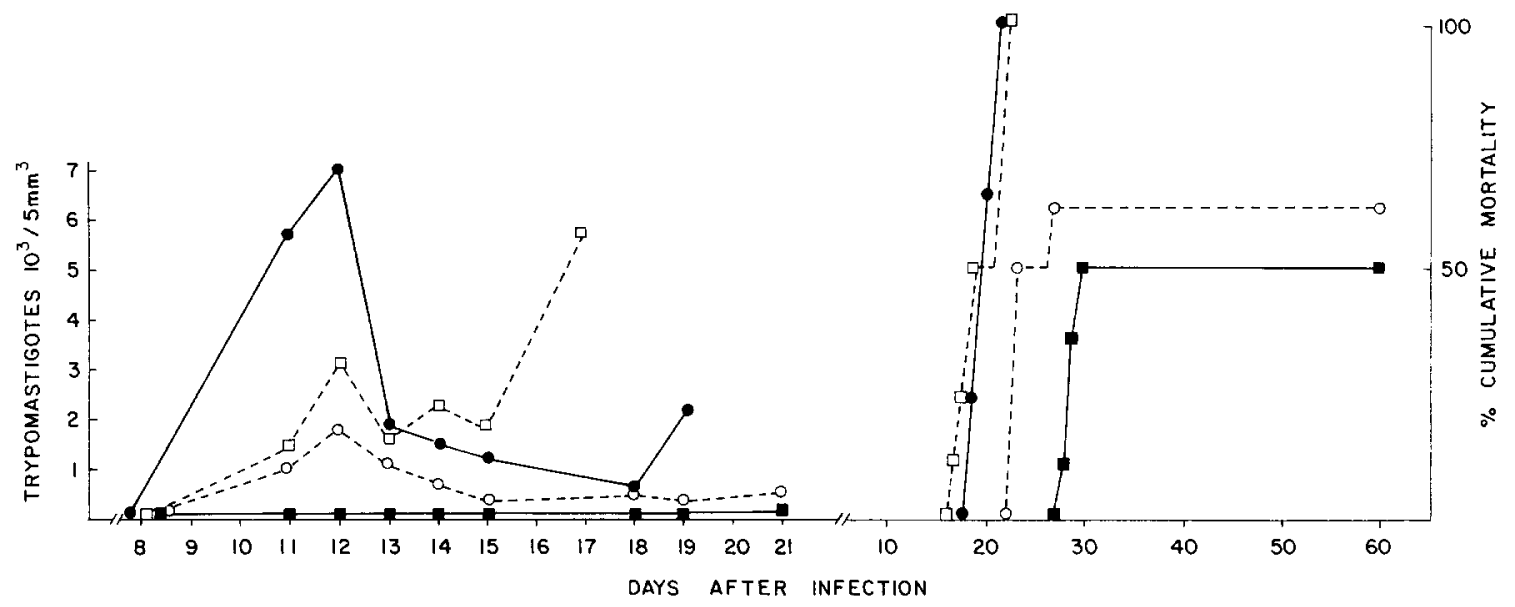

Fig. 3. Parasitaemia and mortality of mice pre-treated with: $\bullet, 4 \times$ concentrated Igs from normal mouse serum; $\odot$, non-concentrated Igs from chronic serum; $\mathbf{\square}, 4 \times$ concentrated Igs from serum of 22 nd day p.i.; and $\square$, non-concentrated Igs from serum of the 22 nd p.i.

chronic and hyperimmune sera. However, as shown in Table 1, when the acute serum was concentrated so as to attain an IgG antibody concentration similar to that in the chronic serum, it became as protective as the chronic and hyperimmune sera. These results strongly suggest that the difference between the protective ability of the acute and the chronic serum is only quantitative. In agreement with this suggestion is the observation that the antibodies present in the acute phase of the infection are already able to recognise the high-molecular-weight proteins of the Btrys as detected by the chronic serum. Thus, antibodies present in day 14 p.i. revealed all the bands above $70 \mathrm{kDa}$ which include the proteins involved in the induction of protective antibodies [12]. These findings agree with previous results of Grögl and Kuhn [13] and Zweerink et al. [14] who, working with cell culture-derived trypomastigote and epimastigote antigens, have also detected a similar antigenic pattern to that revealed with acute and chronic mouse sera.

The mechanism of the protective ability of the anti-T. cruzi antibodies is not well known. Although the protective antibodies have lytic activity [4], it has not yet been demonstrated that lysis of the parasites in vivo is responsible for the protective effect.

The apparent lack of correlation between the lytic activity of the early sera and their protective or clearance ability seems to be due to a quantitative change in the nature of the antibodies, as we suggest here, rather than to a qualitative change. This conclusion agrees with our previous results [1] showing that a relatively large concentration of the chronic serum or its IgG fractions are required to transfer protection.

\section{References}

[1] Takehara, H. A., Perini, A., Silva, M. H. and Mota, I. (1981) Exp. Parasitol. 52, 137.

[2] Romeiro, S. A., Takehara, H. A. and Mota, I. (1984) Clin. Exp. Immunol. 55, 413.

[3] Scott, M. T. and Goss-Sampson, M. (1984) Clin. Exp. Immunol. 58, 372.

[4] Krettli, A. U. and Brener, Z. (1982) J. Immunol. 128, 2009.

[5] Krettli, A. U. (1984) Mem. Inst. Oswaldo Cruz 79, 59.

[6] Silva, L. H. P. and Nussenzweig, V. (1953) Folia Clin. Biol. $20,191$.

[7] Umekita, L. F., Takehara, H. A. and Mota, I. (1988) Immunol. Lett. 17, 85.

[8] Hoshino-Shimizu, S., Camargo, M. E., Shimizu, T. and Nagasse, T. K. (1982) Rev. Inst. Med. Trop. São Paulo 24, 63.

[9] Silva, A. M. M., Costa, H. H., Takehara, H. A. and Mota, I. (1988) Trans. R. Soc. Trop. Med. Hyg. 82, 715.

[10] Krettli, A. U. (1978) Doctoral Thesis. Federal University of Minas Gerais, Belo Horizonte, MG, Brazil.

[11] Brener, Z. (1961) Doctoral Thesis. Federal University of Minas Gerais, Belo Horizonte, MG, Brazil.

[12] Camargo, E. P. (1984) Mem. Inst. Oswaldo Cruz 79 (Suppl. I), 169.

[13] Grögl, M. and Kuhn, R. E. (1985) J. Parasitol. 71, 183.

[14] Zweerink, H. J., Anderson, O. F., Greenblatt, H. C. and Muray, P. K. (1985) J. Parasitol. 71, 43. 